\title{
A IDEla de Sistema no PENSAMENTo CLÁssico GREGO (II)
}

\section{(The idea of system in Greek classical thinking)}

\author{
Marcelo F. de Aquino*
}

Resumo: Esta é a segunda parte de um estudo sobre a gênese da idéia de sistema em Lima Vaz. Considera a relação de continuidade e descontinuidade entre Aristóteles e Platão. Ilumina algumas tangências estruturais do programa aristotélico com o programa platônico e a recuperação do primado da theoría nas linhas sistemáticas da Ética a Nicômaco.

Palavras-chave: Aristóteles, Platão, sistema, teoria, Ética

Abstract: This is the second part of a study about the genesis of the idea of system in Lima Vaz. It considers the relationship of continuity and discontinuance between Aristotle and Plato. It enlightens some points of structural coincidence of the Aristotelian program with the Platonic, and the recovery of the theory primacy in the systematic lines of the Ethics to Nicomachus.

Keywords: Aristotle, Plato, system, theory, Ethics

\footnotetext{
* Professor do Departamento de Filosofia e Reitor da Universidade do Vale do Rio dos Sinos (Unisinos), São Leopoldo, RS. Este artigo é a continuação de um primeiro publicado em Síntese v. 39 n. 123 (2012): 31-52. O aparato crítico nele referido continua o mesmo. Carlos Alberto Gianotti corrigiu o português e Marlise Horn da Silva formatou o texto. Obrigado a ambos. Artigo submetido a avaliação no dia 06.07.2012 e aprovado para publicação no dia 07.07.2012.
} 


\section{Continuidade e ruptura do programa platônico por Aristóteles}

A ristóteles ${ }^{1}$ pertence à tradição cultural iniciada por Platão ${ }^{2}$, conti nuada pela Primeira Academia ${ }^{3}$ e perpetuada na cultura ocidental sob o nome de platonismo. Todas as grandes categorias que formam o arcabouço teórico do seu ensinamento mostram, de uma maneira ou de outra, sua raiz platônica. Recebem dela seus temas e problemas. Representam, porém, versão tão original e criadora do platonismo que acabam por inaugurar nova tradição - o aristotelismo - inconfundivelmente distinta, mas não arrancada do tronco platônico ${ }^{4}$.

A originalidade de Aristóteles não pode ser pensada se não se leva em conta as tangências estruturais ${ }^{5}$ do pensamento aristotélico com o pensamento platônico. O conhecimento do platonismo original por Aristóteles foi fundamental para o embasamento de sua concordia discors em face da herança doutrinal platônica. A ideia de sistema ${ }^{6}$ em Aristóteles germina nesse solo.

A natureza e o estado das fontes delimitam as fronteiras dos estudos dos dois pensadores. No caso de Platão, juntamente com os textos dos diálogos, sua obra escrita, há uma tradição indireta de doutrinas expostas oralmente por Platão na Academia e que ficaram conhecidas como ágrapha dógmata. A transmissão da obra aristotélica seguiu trajetória bem mais complexa. O legado literário de Aristóteles, desde a Antiguidade, foi dividido em dois grupos: escritos exotéricos e escritos esotéricos. Os escritos exotéricos, para muitos estudiosos, expressam uma primeira fase do pensamento aristotélico. Nesse caso, podem conter indícios importantes da evolução de Aristóteles. Por algum problema editorial até hoje não suficientemente esclarecido, deixaram de ser copiados e difundidos provavelmente já desde os inícios da nossa era. Deles restam apenas fragmentos doxográficos reunidos pela primeira vez em edição crítica por Valentin

\footnotetext{
${ }^{1}$ Aristóteles viveu vinte anos na Academia, como aluno e como professor onde se familiarizou com o ensinamento platônico e seu método.

${ }^{2}$ Cabe lembrar que a herança do pensamento de Platão na sua recepção pela Primeira Academia e pelo nascente Liceu passou por complexa evolução.

${ }^{3}$ Ver REALE, G. Aristóteles - Metafísica, v. I, Ensaio Introdutório. São Paulo: Loyola, 2001, 157-176.

${ }^{4}$ Além da tradição platônica e da aristotélica, hoje se reconhece a tradição iniciada por Arquimedes. Ver COYNE, G. V. e HELLER, M., A comprehensible Universe. The interplay of Science and Theology. New York: Springer, 2010. Cfr. p 24 "Today historians of science distinguish three great scientific traditions in antiquity: the Platonic tradition, where mathematics is used a priori to physical investigations; the Aristotelian tradition, which consists of qualitative, essenciatially non-mathematical physics; and the Archimedean tradition, where mathematics is applied a posteriori to physical research."

${ }^{5}$ A expressão é usada por Reale, op. cit, pp. 233-250.

${ }^{6}$ Sýstema em Aristóteles é usado como sinônimo de sýstasis e synistánai.
} 
Rose, no século XIX, e mais recentemente reeditados por O. Gigon ${ }^{7}$. Os escritos esotéricos ${ }^{8}$, na sua maior parte, não foram redigidos diretamente por Aristóteles. São textos escolares para uso dos professores e alunos do Liceu constituídos por notas, cadernos de aula, e outros materiais provenientes em grande parte dos próprios alunos. Foram organizados na ordem em que atualmente os conhecemos após a morte de Aristóteles.

O lógos aristotélico tornou-se historicamente possível no espaço epistemológico aberto pelo lógos platônico mediante sua posição crítica a este último. As linhas do pensamento aristotélico, levando-se em conta a discussão em torno da sua evolução, e considerando-se o período da sua maturidade, estão numa relação de continuidade e de descontinuidade perante o pensamento platônico. No escrito exotérico Protréptico a continuidade é atestada pelo conceito de theoretikós bíos (vida contemplativa), assim formulado no ambiente da Primeira Academia na qual se propõe, por obra de Xenócrates, a divisão da Filosofia em Lógica, Física e Ética. Em Aristóteles, as linhas do lógico, do físico e do ético-político convergem para a protê philosophia (Filosofia Primeira) ou theologia, que, do ponto de vista da ideia de sistema, corresponde à Protologia platônica.

A descontinuidade evidencia-se com a crítica à Teoria platônica das ideias ${ }^{9}$ na sua forma original e nas versões difundidas na Primeira Academia. As Ideias, para Platão, constituem o único domínio do noetón (inteligível) no qual é talhado o objeto da ciência. Aristóteles recusa a univocidade do inteligível implicada na Teoria platônica das ideias. Adota, por conseguinte, a plurivocidade do objeto da inteligência, e, consequentemente, a concepção analógica do objeto da episthéme ${ }^{10}$. A analogia, em Platão, tem função fundamentalmente heurística, como, por exemplo, a analogia entre a alma e a cidade na República, ou é uma analogia estritamente matemática como as proporções empregadas pelo Demirgo no Timeu para a construção do kósmos. Em Aristóteles, a analogia legitimamente significada na estrutura linguística pròs én é constitutiva da inteligibilidade do objeto.

\footnotetext{
${ }^{7}$ Aristotelis Opera III: Librorum deperditorum fragmenta, Berlin, W. de Gruyter, 1987.

${ }^{8}$ A obra escolar de Aristóteles que abrange a maior parte do chamado Corpus Aristotelicum foi editada pela primeira vez em sua ordem atual por Andrônico de Rodes no séc. I a. C. e recebeu no século XIX, por obra de Immanuel Bekker, a edição crítica considerada princeps, que foi posteriormente reeditada por O. Gigon. Cfr. Aristóteles, Opera: collegit et annotationibus instruxit Olof Gigon, 2. ed., Berolini, Walter de Gruyter, v. 1, 1970; v. 2, 1970; v. 3, 1987. Ver Aristote, Éthique a Nicomaque. Nouvelle traduction avec introduction, notes et index par J. Tricot. Paris: Vrin, 1950. Aristote, La Métaphysique, nouvelle édition entièrement refondue avec commentaire par J. Tricot. Paris: Vrin 1953, 2 V. Aristote, L'Éthique à Nicomaque. Intr., tr. Comm. Par R.A. Gauthier - J.Y. Jolif, I $(1,2)$ e II $(1,2)$ Louvain: Publications Universitaires / Paris: Éditions Béatrice Nauwelaerte, 1959.

${ }^{9}$ Ver Metafísica A, 9; Z, 6 e os livros M e N inteiros.

${ }^{10}$ Ver PORCHAT PEREIRA, O., Ciência e Dialética em Aristóteles. São Paulo: Editora UNESP, 2001.
} 
A analogicidade do noetón permite afirmar que em Aristóteles a razão não é unívoca, mas pluridiferenciada ${ }^{11}$. Permite reconhecer a pluralidade de diferentes usos da razão, de formas distintas de racionalidade, de métodos distintos segundo a diferença de seus objetos, bem como a consequente divisão das ciências. A representação da classificação das ciências na concepção de Aristóteles não é mais oferecida pela imagem da linha, como na comparação proposta por Platão no fim do livro VI da República, na qual somente a Matemática, obra da diánoia, e a Dialética, produto da nóesis, ambas tendo por objeto próprio somente as ideias, são ciências no sentido estrito. Embora influenciado por Platão, Aristóteles adota uma classificação das ciências que pode ser representada por um feixe cujos ramos estão unidos pelo vínculo da analogia como procedimento próprio do saber científico e que se aplica, originariamente, ao inteligível no sensível, objeto próprio da inteligência humana. A divisão binária entre ciências teóricas e ciências práticas já aparece no Protrético. A divisão ternária dos saberes entre teórico, prático e poiético acaba por prevalecer, vindo a tornar-se expressão clássica da divisão aristotélica das ciências.

A definição do objeto da episthéme e, consequentemente, do método ${ }^{12}$ que convém seguir na sua investigação é importante capítulo da crítica aristotélica à metafísica platônica do Uno-Bem ${ }^{13}$. Nos tratados sobre o bem, o fim, a virtude e a felicidade na Ethikon Nikomaqueian a descontinuidade aparece mais claramente. Aristóteles, porém, mantém a primazia da theoria sobre a práxis, compensando a ruptura entre ciências teóricas e práticas. $\mathrm{O}$ primado da virtude teórica sophia (sabedoria) sobre a virtude intelectual phrónesis (sabedoria prática ou prudência) rearticula a Ética à Metafísica. Aristóteles distingue os diversos tipos de saber correspondentes aos diversos usos da razão. Mas dá continuidade à intenção normativo-explicativa da ciência platônica.

A transposição do télos (fim) do ser, que Platão situara no horizonte do mundo ideal, para o horizonte da physis (natureza) ${ }^{14}$ é outro campo da descontinuidade aristotélica perante o platonismo. A physis animada pela entelécheia ${ }^{15}$ que lhe é imanente, e que como eidos (forma) é seu núcleo inteligível, suporta o desenho formal que a ciência aristotélica lhe confere.

O exame da linguagem também é de ajuda na análise do aristotelismo frente ao platonismo. A definição do ser humano como zôon lógon échôn (animal possuidor do lógos) inspira a posterior consideração dos elementos

${ }^{11}$ Ver BERTI, E., As razões de Aristóteles. São Paulo: Loyola, 1998.

${ }_{12}$ Ver LE BLOND, J.-M., Logique et méthode chez Aristote. Paris: Vrin, 1939. Ver ainda MANSION, S. (coord.), Aristote et les problèmes de méthode. Louvain: Institut Supérior de Philosophie, 1961.

${ }^{13}$ Ver GADAMER, H.-G., Gesammelte Werke. Bd. 7, Griechische Philosophie III, Die Idee des Guten zwischem Plato und Aristoteles. J.C.B. Mohr, Tübingen: 1991, 128-227.

${ }^{14}$ Para Aristóteles, a physis é princípio de movimento e transformação intrínseco aos seres individuais.

${ }^{15}$ É o dinamismo teleológico da forma. 
constitutivos da linguagem: a matéria linguística, o ato linguístico e a significação ou expressão significante da matéria pela mediação do ato. $\mathrm{Na}$ metalinguagem investigada nos escritos lógicos e principalmente nos Analyticas, Aristóteles explicita e codifica pela primeira vez no pensamento filosófico as regras de construção do sistema. Na Metaphysica ele mostra a polissemia dos termos fundamentais da linguagem humana, e, portanto, do nosso conhecimento, a começar pelo termo on (ser): to de on legetai men pollachos (o ser se diz de muitas maneiras) ${ }^{16}$. A mesma polissemia se deverá dizer dos termos "uno", "verdadeiro", "bom", "substância" e outros. Formase assim a constelação de termos analógicos, que constitui a estrutura fundamental da linguagem da ciência segundo Aristóteles.

\section{O uso do lógos nas ciências em Aristóteles}

Refazendo a argumentação! Para Platão, as ideias constituem o único domínio do noéton (inteligível). Toda ciência tem seu objeto talhado nesse domínio. Para Aristóteles, a estrutura analógica significada na estrutura linguística pròs én é constitutiva da inteligibilidade do objeto. A analogicidade do noetón permite-lhe definir os objetos específicos das ciências teóricas, práticas e poiéticas com procedimentos epistemológicos próprios, quer se trate das ciências teóricas, das ciências práticas ou das ciências poiéticas.

As linhas sistemáticas do pensamento de Aristóteles reivindicam uma perì tà anthrópeia philosophía (filosofia das coisas humanas) ${ }^{17}$, situada entre a physikê episthéme (ciência da natureza) à qual o ser humano pertence, e a protê philosophia, theología (ciência das coisas primeiras e divinas), à qual ele pode se elevar. O zôon logikón (animal de linguagem e razão), o zôon politikón (animal político), a pathé (paixão) e a órexis (desejo) são pressupostos antropológicos que especificam as ciências segundo o uso nelas feito da faculdade do lógos, de acordo com o objeto a que se aplica. A pathê e a órexis pertencem tanto à estrutura quanto à atividade da psychê. Esta tem uma vertente alógos (irracional) que intervém decisivamente tanto na práxis ética e política como na poíesis. A significação e a função da hedonê (prazer) na vida humana tornam-se tópico fundamental da Ética aristotélica ${ }^{18}$.

Três principais pontos de vista desenham o katà tòn lógon zen (viver segundo a razão) aristotélico. Em primeiro lugar, e apesar de nos três livros Perì Psychês Aristóteles hesitar a respeito da relação do nous com a psychê, não se decidindo entre o nous como parte da psychê ou dela separado (nous

\footnotetext{
${ }^{16}$ Met., IV, 1, 1003a 32.

${ }^{17}$ Eth. Nik. X, 1181b 12-13.

${ }^{18}$ Eth. Nik., VII, cap. 12-15; X, cap. 1-5.
} 
choristós), ele distingue entre função receptiva ou nous pathetikós - que está em dynamei (potência) em todas as espécies recebidas dos sentidos - e função ativa ou nous poiêtikos ${ }^{19}$ - que faz passar o inteligível imanente à espécie sensível da potência ao ato. Em segundo lugar, na Met., VI, $1^{20}$ considera a atividade intelectual na perspectiva do fim que a razão tem em vista e que especifica o saber por ela produzido. A verdade das coisas, o agathón (bem) ou a areté (excelência) do indivíduo e da comunidade, a utilidade ou o prazer são fins, respectivamente, da theoría (contemplação), da práxis (ação) e da poíesis (fabricação). A construção sistemática de Aristóteles pede uma arquitetura dos saberes. A protê philosophia, theología, objeto da contemplação é esse saber arquitetônico. Em terceiro lugar, nos livros do Órganon ele codifica a forma do pensamento teórico e prático segundo a arte da discussão e da demonstração desenvolvida pelo pensamento matemático, fazendo da ciência o centro do universo simbólico do homem.

De acordo com sua natureza, há objetos que permanecem sempre idênticos a si mesmos: me endechomenon allos echei (não sofrem ser ora de uma maneira, ora de outra). Há os que sofrem variação em seu apresentar-se à experiência: endechomenon allos echei. Os objetos me endechomenon allos echei são regidos pela necessidade do noetón. Formam o campo de uma ciência rigorosa, seja de caráter dedutivo (Matemática), seja de caráter dialético, em sentido aristotélico, (Filosofia Primeira, dita posteriormente Metafísica, ou Teologia), que aplica apoditicamente o argumento de retorção pelo uso do princípio de não contradição na refutação das opiniões contrárias. O uso do lógos nessas ciências teóricas, que tem por fim a pura theoria (contemplação) da verdade, é denominado epistemonikon (científico). Os objetos endechomenon allos echei estão ao alcance do homem e são, em princípio, ta eph'hemin (sob seu domínio), constituindo ta anthrópina. Podem formar tanto o campo das ciências práticas (Ética e Política) como o dos saberes ou artes que regulam a produção de objetos, especialmente as que operam sobre a linguagem (Retórica e Poética). Na concepção aristotélica, o homem se realiza como ser racional somente na vida em comum na polis. Ele é zôon politikón por ser exatamente zôon logikón. A vida ética e a vida política são artes do katà tòn lógon zen. O uso do lógos pela razão prática rege a unidade sistêmica dos domínios ético e político. As aretai êthikai (virtudes recebidas dos costumes da cidade) e as aretai dianoethíkai (virtudes ensinadas) estudadas pela Ética encontram o campo do seu pleno exercício somente na vida política. Ética e Política são para Aristóteles, como tinham sido para Sócrates e Platão, o campo por excelência onde se manifesta a finalidade do homem coroada pelo exercício da razão ou definida pela primazia do lógos. Ao discorrer sobre o eu zên

\footnotetext{
${ }^{19}$ A função ativa do nous está presente no Perì Psychês. Nele, porém, não se encontra a expressão nous poietikós, usada pelos comentadores como correspondente a nous pathetikós. ${ }^{20}$ Met. VI, 1, 1025b 1 - 1026a 33.
} 
(bem viver) ou eudaimonía (felicidade), Aristóteles, na esteira de Sócrates, leva o finalismo moral à sua expressão plena.

\section{Theoria e práxis, ou philosophia e phrónesis, na ideia de sistema em Aristóteles}

Para Aristóteles, a estrutura teleológica da ciência orienta a investigação e a determinação de seu fim específico, ou seja, de seu objeto. Nas ciências teóricas, o fim é a perfeição do objeto a ser contemplado (theoria) em sua verdade. Nas ciências práticas, o fim é a perfeição do agente pelo conhecimento da natureza e das condições que tornam melhor ou excelente o seu agir (práxis). Nelas tem lugar uma relação de intercausalidade entre o formal e o eficiente que é própria desse objeto. Sob o aspecto formal (objetivamente), que é o fim em si mesmo, o agir é objeto de um saber - a Ética - que expõe a natureza e as condições do seu operar segundo o critério do melhor, isto é, da razão. Sob o aspecto eficiente (subjetivamente) que é o fim no sujeito, o agir é o sujeito imediato do mesmo saber, de tal sorte a poder o agente, pela mediação do agir que se sabe, realizar-se em sua perfeição de ser racional. Nas ciências poiéticas, o fim é a perfeição utilitária do objeto a ser fabricado (poíesis) em sua utilidade.

A relação entre theoria e práxis, ou entre philosofia e phronesis, por um lado, é o ponto de inflexão decisivo que define a fisionomia própria da concepção sistemática de Aristóteles perante a concepção de Platão. Mas, por outro lado, é o ponto de reaproximação de Aristóteles e Platão. Para o ser humano, dotado de razão, o Bem ou o fim devem ter predicados que possam ser aceitos e justificados pela razão. Sua posse causa no ser racional, pela mediação da areté, a autorrealização ou autossatisfação designada como eudaimonía.

O tratado do Bem ${ }^{21}$, inicialmente, investiga o Bem supremo em relação ao qual todos os outros bens se ordenam. À hierarquia dos saberes deve corresponder uma hierarquia dos bens. A Política, entendida como Ética e Política, é o saber arquitetônico na ordem da práxis. Seu objeto ou fim deve ser o Bem mais elevado para o ser racional. A noção de Bem, porém, não é uma noção unívoca, o que leva Aristóteles a rejeitar a Ideia do bem, segundo Platão e os platônicos ${ }^{22}$. Também não é uma noção equívoca. Sua predicação é feita $k a t^{\prime}$ analogian ${ }^{23}$.

A investigação sobre o Bem do qual resulta a eudaimonía torna-se fundamental. Nela a Ideia do bem, mesmo na hipótese de que exista, mostra-se

\footnotetext{
${ }^{21}$ Eth. Nik., I, cc. 4-6.

${ }^{22}$ Eth. Nik., I, 4, 1095a 12-20.

${ }^{23}$ Eth. Nik., I, 4, 1096b 25-31.
} 
inútil. A argumentação aristotélica consiste na definição preliminar do Bem e no exame subsequente dos gêneros de vida e do modo em que o Bem se realiza plenamente. Os gêneros de vida ${ }^{24}$ que a tradição grega enumera como capazes de produzir o estado de eudaimonía são a vida de contemplação, a vida política e a vida de prazer. O roteiro sistemático de Aristóteles procede, portanto, da definição do Bem e da determinação do Bem próprio do homem à investigação sobre o modo mais excelente de realização do Bem que é a virtude, sobre as condições dessa realização e sobre as formas de eudaimonia que dela resultam. Em resumo: quais os verdadeiros bens da vida humana? Como classificá-los hierarquicamente? Ou, em termos socráticos, como devemos viver?

A tradição grega enuncia a resposta à primeira questão dizendo que os verdadeiros bens da vida humana são os que lhe trazem a verdadeira eudaimonia e, dentre eles, o mais perfeito é aquele cuja posse é fonte da eudaimonia mais perfeita. A questão socrática encontra sua resposta na ciência dos bens da vida humana, ou Ética, da sua ordenação segundo o grau de perfeição que lhes compete, e da forma de eudaimonia que deles resulta. Aristóteles não se pergunta o que é em si a virtude, mas como nos tornamos bons, ou eudaimones, praticando- $\mathrm{a}^{25}$.

A relação intrínseca entre Bem e felicidade é o ponto de partida para a solução aristotélica ao problema da liberdade em face da necessidade do destino e dos azares da sorte. O conhecimento do Bem e o agir segundo o Bem que dele decorre são o critério fundamental para avaliar a medida da liberdade presente na práxis. Felicidade e liberdade estão, pois, em correlação intrínseca. Como consequência dessa correlação, deve-se atribuir ao exercício da vida no bem a autonomia ou autocausalidade da autarkeia que define o ser livre ${ }^{26}$. Essa fundamentação da autonomia na objetividade do bem, no pensamento aristotélico, cabe lembrar por oportuno, distinguea da autonomia kantiana, fundada no apriorismo da razão prática. A areté em referência implícita, mas constante aos seus dois polos, o agathón e a eudaimonía, indica o roteiro a ser percorrido agora. A conclusão do tratado sobre a eudaimonia ${ }^{27}$ celebra-a como um bem divino, pois é a ela que se louva e honra nos deuses e é ela que justifica a atribuição de divinos dada aos mortais que dela participam.

A eudaimonia é uma energeia (atividade) da alma kat'areten teleian (segundo a virtude perfeita $)^{28}$. A areté é, pois, atividade fonte da eudaimonia. Aristóteles percorre os diversos aspectos do problema da areté em referência constante, mas implícita aos seus polos: a eudaimonia e o agathós. Levando em conta as tangências estruturais entre as ideias de sistema em

\footnotetext{
${ }^{24}$ Eth. Nik., I, 5, 1095b 17-18.

${ }^{25}$ Eth. Nik., II, 2, 1103b 26-28.

${ }^{26}$ Eth. Nik., I, 7b 6-21; ver ainda Met. I, 982b 26: eleutheros o autou eneka.

${ }^{27}$ Eth. Nik., I, 12.

${ }^{28}$ Eth. Nik., I, 13, 1102a 5-6.
} 
Aristóteles e Platão, é possível inventariar alguns tópicos que manifestam a concordia discors entre ambos.

O primeiro tópico diz respeito à definição e à divisão da areté e a seu fundamento antropológico ${ }^{29}$. Se a eudaimonía é a enérgeia da alma segundo a virtude ${ }^{30}$, e se, por conseguinte, a virtude que aqui se investiga é a virtude humana ${ }^{31}$, que é uma virtude da alma, há uma correspondência estrutural entre as atividades da alma, que são essencialmente distintas, e as virtudes em cujo exercício se fazem presentes essas atividades. Aristóteles, por um lado seguindo o caminho trilhado por Platão na República, que estabelece a divisão das virtudes cardeais, mostra a relação sistêmica entre Antropologia e Ética. Por outro lado, distancia-se da analogia platônica entre a alma e a cidade. Assim sendo, não é a divisão tricotômica das partes da alma que é utilizada aqui, mas a dicotomia vulgarizada na Academia desde Xenócrates entre a parte alógon (irracional) da alma que não obedece a uma regra e a parte katà lógon (racional) da alma que obedece a uma regra. A parte alógon subdivide-se entre a parte puramente vegetativa, incapaz de ser sede de qualquer virtude humana ${ }^{32}$ e a parte apetitiva que, de alguma maneira, participa da regulação provinda da parte katà lógon ${ }^{33}$.

A virtude, sendo própria da parte racional da alma, divide-se em duas espécies. As virtudes dianoéticas ou virtudes do entendimento são exercidas pela parte racional propriamente dita. As virtudes éticas ou virtudes do caráter são exercidas pela razão em acordo com a parte apetitiva. Esta distinção aristotélica põe termo à querela sofístico-socrática sobre a ensinabilidade da virtude. Supera o cognitivismo socrático da virtude-ciência já que, segundo Aristóteles, se as virtudes dianoéticas são fruto do ensinamento, as virtudes éticas são adquiridas pelo hábito ${ }^{34}$.

O segundo tópico investiga no tratado sobre as virtudes éticas ${ }^{35}$ a aquisição, a natureza e as condições do exercício da virtude, incluindo a doutrina da mesótes $^{36}$. O catálogo das doze virtudes éticas ${ }^{37}$ termina com todo um livro consagrado à justiça ${ }^{38}$.

Nenhuma virtude pode ser exercida sem a presença ativa da parte katà lógon da alma e, portanto, sem a presença reguladora das virtudes dianoéticas. O terceiro tópico tem, pois, por foco as virtudes dianoéticas ${ }^{3}$.

\footnotetext{
${ }^{29}$ Eth. Nik., I, 13.

${ }^{30}$ Eth. Nik., I, 13, 1102a 5.

${ }^{31}$ Eth. Nik., I, 13, 1102a 14.

32 Eth. Nik., I, 13, 1102a 32 - b 14.

${ }^{33}$ Eth. Nik., I, 13, 1102b 28-31; 1103a, 1-13.

${ }^{34}$ Eth. Nik., II, 1, 1103a 14-17.

${ }^{35}$ Eth. Nik., II - V.

${ }^{36}$ Eth. Nik., II, 5, 1006a $24-8,1009$ a 19.

${ }^{37}$ Eth. Nik., III, 9 - V: coragem,temperança, liberalidade, magnificência, magnanimidade, equanimidade, placidez, amabilidade, veracidade, jovialidade, pudor, justiça.

38 Eth. Nik., V.
} 
Inicialmente, Aristóteles estende o campo de sua investigação a todas as formas de atividade da razão. Utiliza para tanto dois critérios para distingui-las: a diferença de seus objetos e, correspondendo a esses objetos, a obra própria - a verdade - que cada uma realiza ${ }^{40}$.

A razão, do ponto de vista do objeto, apresenta duas atividades especificamente distintas. A que se dirige aos objetos que me endechomenon allos echei, e a que se dirige aos objetos endechomenon allos echei. A primeira atividade, puramente intelectual, é denominada epistemonikon (científica); a segunda, que admite a colaboração com a parte apetitiva, tanto pode ser logistikon (deliberante) como doxastikon (opinativa) ${ }^{41}$. Aristóteles reduz a duas as virtudes dianoéticas que devem ser levadas em consideração: a philosophia, que é a virtude do epistemonikón, e a phrónesis (sabedoria prática ou prudência), que é a virtude do logistikon, o diretivo do agir humano. A doutrina da phrónesis é importante ponto de definição da fisionomia própria de Aristóteles relativamente a Platão. A distinção entre philosophia e phrónesis direciona os termos do dilema em que reaparecerá a questão fundamental da eudaimonía ${ }^{42}$. Após a investigação das condições da virtude, ou seja, a disciplina das paixões, o prazer e a amizade $^{43}$, ele discute a questão da téleia eudaimonia (perfeita felicidade) que se apresenta como télos (fim) último da vida humana.

Aristóteles se reaproxima de Platão nos capítulos 6,7 e 8 do livro X da Ética a Nicômaco ao celebrar a theoría sobre a qual repousa a vida contemplativa. Afirma a superioridade da vida contemplativa sobre a vida política. A primeira repousa na theoría; a segunda é regida pela phrónesis. Esta atribuição fundamenta-se na concepção antropológica que admite ser o nõus (inteligência) e a sophia (sabedoria) "o divino, ou o que há de mais divino" $^{44}$. Mais ainda, é consequência irrecusável da concepção da areté como enérgeia (atividade), uma vez que a atividade da theoría é a mais perfeita, desde que dirigida ao tò theion (o divino), o mais perfeito dos objetos, dela procedendo a mais perfeita eudaimonía.

Emdereço do Autor:

Av. Unisinos, 950

93022-000 São Leopoldo - RS

e-mail: aquino@unisinos.com.br

${ }^{39}$ Eth. Nik., VI.

${ }^{40}$ Eth. Nik., VI, 2.

${ }^{41}$ Eth. Nik., VI, 2, 1140b, 26.

${ }^{42}$ Eth. Nik., X, 6-8.

${ }^{43}$ Eth. Nik., VII $-X, 1-5$.

${ }^{44}$ Eth. Nik., X, 7, 1177a, 15-16. 